\title{
Associated Adeno Virus Vector for Producing Induced Pluripotent Stem Cells (IPS) for Human Somatic Cells
}

\author{
Edilamar Menezes Oliveira ${ }^{1}$ and M Ian Phillips ${ }^{2}$ \\ 1 University of São Paulo, São Paulo \\ ${ }^{2}$ Keck Graduate Institute, Claremont, California \\ ${ }^{1}$ Brazil \\ 2 United States
}

\section{Introduction}

The discovery that adult somatic cells could be induced to become pluripotent stem cells with apparently all the properties of human embryonic stem cells ( hESCs ), independently by S .Yamanaka et al ( Takahashi et al 12007 ) and by J. Thompson et al ( Yu et al 2007) was greeted with amazement and in some quarters with relief. The breakthrough, first reported in mice by S Yamanaka in Japan did not receive much notice, but the revelation that adult human cells could be reversed into an embryonic like state was astounding because it was so simple. It was greeted with relief where the progress of hECS was blocked at the federal level because producing hECS raised ethical concerns and political consequences. Yet four years later, although we have discovered much about iPS cells, they are far from being the ideal solution that they seemed to promise.

When human iPS cells were first published they appeared to have so many advantages over hECs. Foremost was the lack of an embryo being involved which meant they could not be logically banned or targeted as unethical (although some tried). Second the science behind making them was astonishingly simple. It only required delivery of four transcription factors found in embryos to reverse years of life as an adult cell back to an embryonic like cell. The record for number of years as an adult cell was set by Eggan et al (Dimos et al 2009 ), who induced the skin cells of an 82 year old lady back to iPScells .

iPS cells offer the advantages of avoiding the religious or ethical considerations that plague the use of embryonic stem cells. They also could provide autologous transplantation, for repair and regeneration of tissue without rejection. If the donor cells retain the mutation or mutations that caused the patient's disease state, it is possible to correct those mutations before implantation by homologous recombination. Even if they can not be corrected, those mutations are open to study in lineages derived from the iPS cells. A further advantage of studying iPS cells is access to testing new drugs in those diseased human cells. At present the barriers to adopting iPS in the clinic are the limitations of methods to produce the cells. iPS technology is expected to move health sciences forward in unique ways for diagnosis, drug screening, toxicity, repair of mutations and treatment of human diseases. iPS cells produced from an individual are embryonic-like stem cells and they can be regrown into 
any of the 200 somatic cell types. iPS cell have many similarities with ESC cells including the cell morphology, surface antigens, gene expression, telomerase activity, and the epigenetic status. iPS cells have been produced by delivering transcription factors by different types of viral vectors including retroviruses (Takahasi et al 2007), lentiviruses (Chang C-W et al 2009), adenoviruses (Stadtfield et al 2008), plasmid transfections (Jia et al 2010), transposons (Woltjen et al 2010 ), mRNA or recombinant proteins (Warren et al 2010).

It appears that any cell type in the body can be reprogrammed. It was first achieved in skin cells for easy availability. This meant that autologous stem cells could be grown from iPS cells. Autologous transplantation using human iPS cells would not be rejected by graft versus host problems. Even if the donor cells a contain mutation that cause the disease reprogramming can be carried out in mutated cells to study diseases and to correct the mutations ex vivo by homologous recombination. IPS cells are produced to be as close to human ESCs as possible to have the advantages of pluripotency that hESCs have. However hESCs could only be transplanted allogenically into adults and rejection would always be a problem.

Despite the euphoria and literally thousands of studies, there are nagging problems with making iPS cells work in the way that was hoped. One of the reasons is that iPS cells, just like hEScs, go through a stage of producing teratomas. Several studies have found that mice produced from iPS cells are more prone to cancer. The original method for producing iPScells was by a retrovirus to deliver the four transcritption factors. Retroviruses are notorious for random insertion in the genome and being oncogenic. In Yamanka's study the method included c-Myc as a transcription factor that incrcreased cell growth. However the same property is the property that makes c-Myc an oncogene and therefore another prime suspect in causing cancer. Thompson's group avoided using c-Myc but also used a retrovirus and instead of c-Myc used LIN 28 as a transcription factor ( $Y u$ et al 2007). Eventually Yamanaka's group dispensed with c-Myc but lost efficiency. Only Oct4 and Sox2 seemed to be absolutely necessary. The other factors could be varied, with Nanog substituting for c-Myc. To avoid the dangers of retroviruses various alternatives for nonintegrating delivery have been tried. Adeno-virus was used successfully. But Adenovirus while not being carcinogenic has other problems. In 1999 it was prematurely used in a Phase I gene therapy trial and caused the death of one of the participants, Jesse Gelsinger. Adenovirus produces many proteins and these induce immune reactions. It was an immune reaction to adenovirus in Jessie Gelsinger's body that made adenovirus totally unacceptable for human use (Marshall 1999). There is an alternative however, Adeno-Associated Virus (AAV). Despite its name, AAV is unrelated to Adeno-virus, and is proving to be a very safe and reliable vector for gene delivery. Gene therapy with rAAV for restoring sight to patients blind since birth or early childhood (Leber congenital amaurosis) has proven that in humans rAAV is very safe (Maguire et all 2008).

Therefore we tested if AAV could be used to induce IPS in adult cells. Eventually there will come a time when iPS will be tested for therapeutic use in treating humans. Although there are now virus free methods of making iPS we do not know which method will have the greatest efficiency, safety, reproducibility or efficacy. Therefore having several different ways of producing iPS is still a viable quest, and here we show how AAV can be used to produce iPS cells.

\section{Methods}

We generated iPS from with four transcription factors: Oct3/4, Sox2, Klf4 and c-Myc by recombinant adeno-associated viral (rAAV) transduction. 
The parvovirus adeno-associated virus (AAV) has single-stranded genome of approximately $4.7 \mathrm{~kb}$ carrying capacity. Recombinant AAV (rAAV) in which the two open reading frames of AAV, designated rep and cap, have been replaced by a gene of interest has become an important tool for gene delivery (Phillips et al 2010, Maguire et al 2008, Zolotukhin et al 1999).

\subsection{Construction of four rAAV plasmids}

\subsection{1 rAAV plasmid with transcription factor: Oct3/4}

Vector: pTR-UF3 (an adeno-associated virus (AAV)-based plasmid vector) pTR-UF3 (a kind gift of Nicholas Muzyczka) contains the humanized green fluorescent protein (hGFP) gene under control of cytomegalovirus (CMV) promoter through the polio virus type 1 internal ribosomal entry site (IRES). A $1.4 \mathrm{~kb}$ fragment, which contains Oct3/4 (1134 bp), was extracted from pMXs-Oct3/4 (a kind gift from Shinya Yamanaka's Lab) by BstxI restriction enzyme digestion. The $1.4 \mathrm{~kb}$ fragment was inserted into the unique Hind III site of the AAV-derived plasmid pTR-UF3, forming the AAV-derived plasmid pTR-Oct3/4-hGFP.

\subsection{2 rAAV plasmid with transcription factor: Sox2}

Vector: pTR-UF11 (an adeno-associated virus (AAV)-based plasmid vector) pTR-UF11 (a kind gift of Nicholas Muzyczka) is derived from pSM620 [2] in which the internal sequences have been replaced by a green fluorescent protein (GFP) gene under the control of a chicken $\beta$ actin -cytomegalovirus promoter and a neo gene under the control of a thymidine kinase promoter. A $1.2 \mathrm{~kb}$ fragment, which contains Sox2 (960 bp), was extracted from pMXs-Sox2 (a kind gift from Shinya Yamanaka's Lab) by BstxI restriction enzyme digestion. The AAVderived plasmid, which consists of Sox 2 gene, was made by digesting pTR-UF11 with NotI (cutting hGFP), blunting with large klenow fragment and ligating together with the above $1.2 \mathrm{~kb}$ fragment, forming $\mathrm{pTR}$-Sox2-Neo.

\subsection{3 rAAV plasmid with transcription factor: KIf4}

Vector: pTR-UF11 (an adeno-associated virus (AAV)-based plasmid vector). The transcription factor of Klf4 was amplified by PCR (Forward Primer: GTG GTA CGG GAA ATC ACA AG and Reverse Primer: TTA AAA GTG CCT CTT CAT GTG) from the template of pMXs-Kfl4 (a kind gift from Shinya Yamanaka's Lab). The $1.5 \mathrm{~kb}$ PCR product consists of Klf4 factor (1425 bp). The AAV-derived plasmid, which consists of Klf4 gene, was made by digesting pTR-UF11 with $\mathrm{XbaI}$ and SacI, blunting with large klenow fragment and ligating together with the above $1.5 \mathrm{~kb}$ PCR products, forming pTR-Klf4.

\subsection{4 rAAV plasmid with transcription factor: c-Myc}

Vector: pTR-UF11 (an adeno-associated virus (AAV)-based plasmid vector). A $1.56 \mathrm{~kb}$ fragment, which contains c-Myc (1320 bp), was extracted from pMXs-c-Myc (a kind gift from Shinya Yamanaka's Lab) by BstxI restriction enzyme digestion. The AAV-derived plasmid, which consists of c-Myc gene, was made by digesting pTR-UF11 with XbaI and SacI, blunting with large klenow fragment and ligating together with the above $1.56 \mathrm{~kb}$ fragment, forming pTR-c-Myc. The maps of rAAV vectors (pTR-UF ${ }^{3}$ and pTR-UF11) and the rAAV plasmids with defined factor (pTR-Oct3/4-GFP, pTR-Sox2-Neo, pTR-Klf4 and pTR-c-Myc, respectively) are summarized in Figure 1.

The procedures for rAAV production, including harvesting the cells (HEK 293), extraction by freezing and thawing purification by iodixanol heparin affinity chromatography as a 
second step in purification following the iodixanol gradient, are used regularly in our lab and published by Zolhutkin et al (1999) Phillips et al (2010). The maps for constructing AAV with Oct3/4, Sox2, and Klf-4 and c-myc are shown in Figure 1.
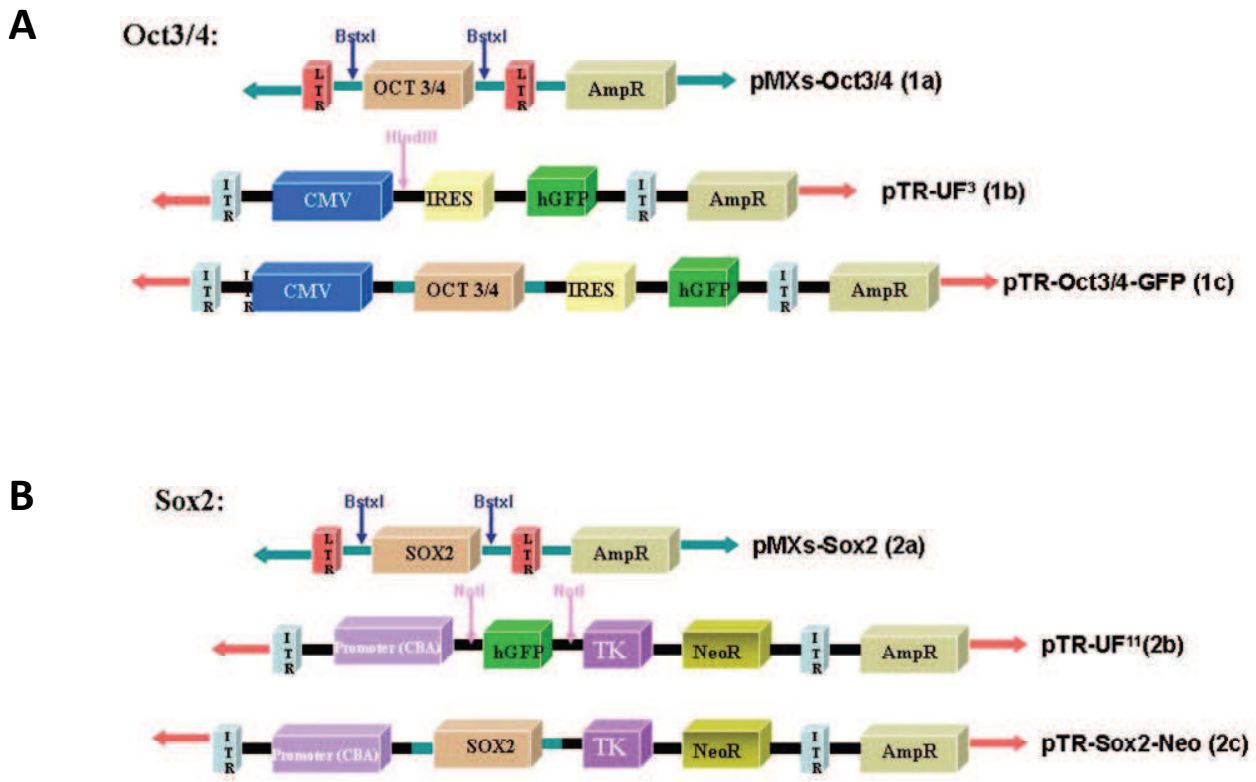

Fig. 1. 1A. AAV-based plasmid with transcription factor of Oct3/4: A $1.4 \mathrm{~kb}$ fragment, which contains Oct3/4 (1134 bp), was extracted from pMXs-Oct3/4 (a gift from Shinya Yamanaka's Lab) by BstxI restriction enzyme digestion (1a). The $1.4 \mathrm{~kb}$ fragment was inserted into the unique Hind III site of the AAV-derived plasmid pTR-UF3 (1b), forming the AAV-derived plasmid pTR-Oct3/4-GFP (1c). pTR-UF3 (a gift of Nicholas Muzyczka), which is an adeno-associated virus (AAV)-based plasmid vector, contains the humanized green fluorescent protein (hGFP) gene under control of cytomegalovirus (CMV) promoter through the polio virus type 1 internal ribosomal entry site (IRES) (1b).

1B. AAV-based plasmid with transcription factor of Sox2: A $1.2 \mathrm{~kb}$ fragment, which contains Sox2 (960 bp), was extracted from pMXs-Sox2 by BstxI restriction enzyme digestion (2a). The AAV-derived plasmid, which consists of Sox 2 gene, was made by digesting pTR-UF11 with NotI (cutting hGFP) (2b), blunting with large klenow fragment and ligating together with the above $1.2 \mathrm{~kb}$ fragment, forming pTR-Sox2-Neo (2c). pTR-UF11 is derived from pSM620 [Zolhutkin et al 1999] in which the internal sequences have been replaced by a green fluorescent protein (GFP) gene under the control of a chicken $\beta$-actin cytomegalovirus promoter (CBA) and a neo gene under the control of a thymidine kinase promoter (2b). The AAV-based plasmid with transcription factors of Klf-4 and c-Myc were in the same way as to Sox2. (Phillips et al 2010).

\subsection{PCR primers}

The specific primers were designed to confirm the purified virus (rAAV) that contains the inserted defined factor (Myc, Klf4, Oct 4 and Sox2, respectively) as follows: 
The "Universal" Forward Primer:

5'-GTG GTA CGG GAA ATC ACA AG-3' (The primer was designed according the sequences from the backbone of rAAV plasmid vector beyond the full length of the defined factors)

The Reverse Primers:

Oct3/4

Reverse primer: 5'-AGATGGTGGTCTGGCTGAAC-3'

(Accession: M34381 Oct3/4: 581-562)

Sox2

Reverse primer: 5'-CTCCGGGAAGCGTGTACTTA-3'

(Accession: NM_011443 oct3/4: 805-786)

KLF4

Reverse primer: 5' - GGAAGACGAGGATGAAGCTG-3'

(Accession: BC010301 Klf4: 862-843)

c-Myc

Reverse primer: 5' - ATCGCAGATGAAGCTCTGGT-3'

(Accession: NM_010849 Myc: 983-964)

\subsection{PCR amplification}

One $\mu$ l of viral DNA from the purified virus was amplified by Polymerase Chain Reaction (PCR) in $25 \mu \mathrm{l}$ reaction volume by above universal forward primer paired with the specific reverse primer of Myc, Klf4, Oct 3/4 and Sox2, respectively. The amplification was performed in the following conditions: 4 minutes at $94^{\circ} \mathrm{C} ; 15$ cycles of 30 seconds at $94^{\circ} \mathrm{C}, 30$ seconds at $58^{\circ} \mathrm{C}$ (annealing), 1 minute at $72^{\circ} \mathrm{C}$ and a final extension period of 10 minutes at $72 \circ \mathrm{C}$ in iCycler Thermal Cycler (Bio-Bad).

One $\mu$ l of viral DNA from the purified virus of UF3-Oct3/4-GFP was amplified as above by the forward primer 5'-CAG CGG AGA GGG TGA AGG TG-3' (Accession: U50963 GFP: 87106) and the reverse primer 5'-CAG GGC AGA CTG GGT GGA CA-3' (Accession: U50963 GFP: 621-602)

\subsection{PCR results}

Amplification products $(10 \mu \mathrm{l})$ were analyzed on $1 \%$ agarose stained with ethidium bromide. The results were shown in the Figure 2.

\section{5 rAAV-GFP transduction}

Two human somatic cell types were used: IMR-90 a fetal skin fibroblast and HEP G2 liver cells were used to induce iPS. Before the transduction we tested a normal and a starving protocol, as described below.

\subsubsection{IMR-90 a fetal skin fibroblast}

The IMR-90 cells were purchased from American Type Culture Collection (ATCC, Catalog No. CCL-186) and they are diploid human cells that are being extensively characterized by the ENCODE Consortium and have published DNA fingerprints that allow confirmation of the origin of reprogrammed clones. IMR-90 cells also proliferate robustly for more than 20 passages before undergoing senescence, but grow slowly in human ES cell culture conditions (Yu, J 2007). 
$\begin{array}{llllllll}1 & 2 & 3 & 4 & 5 & 6 & 7 & 8\end{array}$

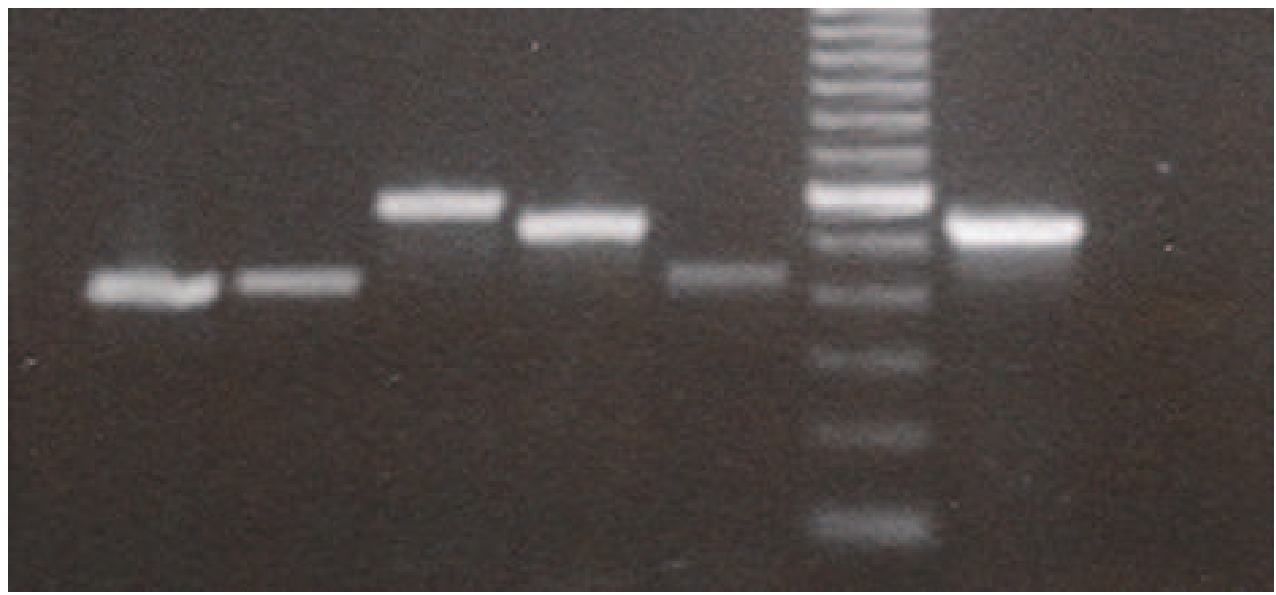

Lane 1: pUF11_C-Myc (check C-Myc) (417bp)

Lane 2: pUF11-KLF4 (check KLF4) (429bp)

Lane 3: pUF3-Oct3/4-IRES-GFP (check Oct3/4) (583bp)

Lane 4: pUF3-Oct3/4-IRES-GFP (check GFP) (535bp)

Lane 5: pUF11-Sox2 (check Sox2) (433bp)

Lane 6: 100 bp DNA Ladder

Lane 7: Positive control: pUF11consists of GFP (535bp)

Lane 8: Negative control

Fig. 2. PCR results with AAV delivery of defined factors for reprogramming

\subsubsection{Normal protocol}

A vector constructed with adeno-associated virus (AAV)-based plasmid vector ( $\mathrm{PUF} 11$ ) containing green fluorescent protein (GFP) with 535bp (Phillips et al., 2010) was transduced in the cells. Cells were plated in 6 wells plates (5x $10^{4}$ cells/well) and were cultured in Minimum Essential Medium (MEM Engle) supplemented with 10\% heat-inactivated fetal bovine serum (10\% FBS), $0.1 \mathrm{mM}$ non-essential amino acids, and $1.0 \mathrm{mM}$ sodium pyruvate. The cells were cultured by $24 \mathrm{hs}$ at $37{ }^{\circ} \mathrm{C}, 5 \% \mathrm{CO}_{2}$. One day later, when cells were approximately $70-80 \%$ confluent, the cells were washed twice with PBS and transduced with adeno-associated virus (AAV)-GFP vector with medium (MEM Engle) without FBS and antibiotic with MOI 50, 100, 250, 500 and 1000 . Cells were incubated at $37{ }^{\circ} \mathrm{C}, 5 \% \mathrm{CO}_{2}$ for $24 \mathrm{hs}$. The medium was change to MEM Engle $10 \%$ FBS. The medium was change every day. Ten days after the transduction the number fluorescent cells per well were quantified with confocal microscopy. Figure 3, the figure shows two green fluorescent cells isolated and analyzed by Confocal Microscopy (Leica Microsystems-TCS SP5) indicating successful AAV-GFP transduction. The GFP positive cells/field is shown Figure 4. 

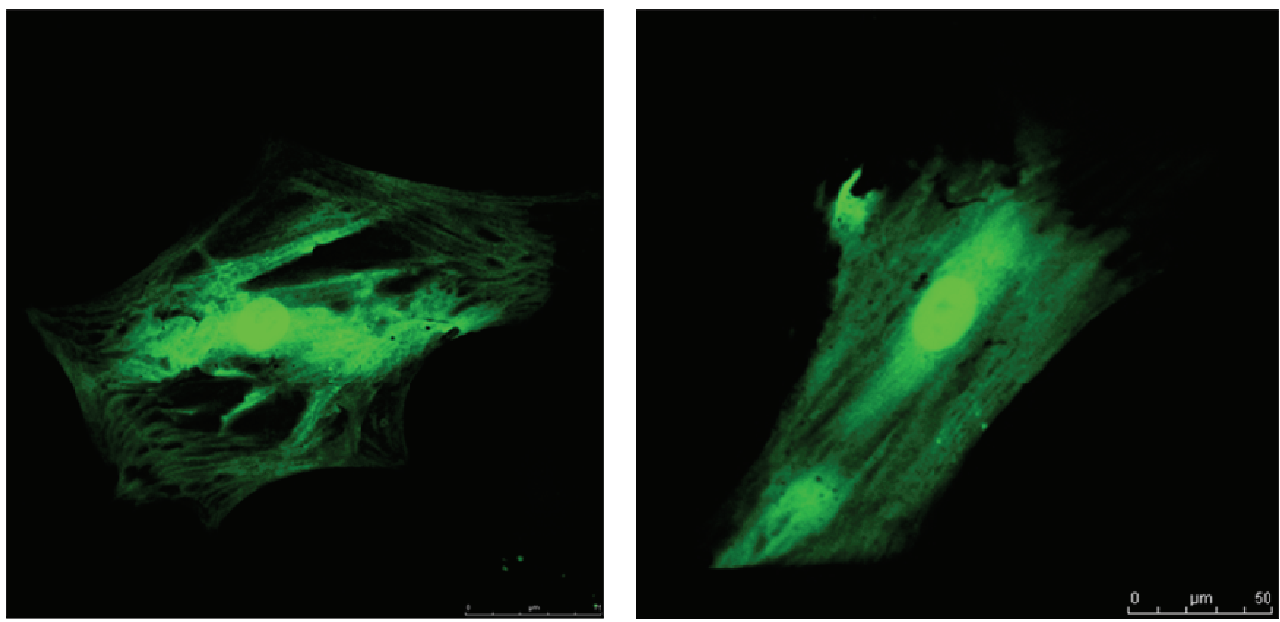

Fig. 3. AAV-GFP transduction. The figure shows two green fluorescent cells isolated and analyzed by Confocal Microscopy (Leica Microsystems-TCS SP5) indicating successful AAV-GFP transduction.

\subsubsection{Starving protocol}

To starving protocol the cells were plated in 6 wells plates (5x $10^{4}$ cells/well) and were cultured in Minimum Essential Medium (MEM Engle) supplemented with 10\% heatinactivated fetal bovine serum (10\% FBS), $0.1 \mathrm{mM}$ non-essential amino acids, and $1.0 \mathrm{mM}$ sodium pyruvate. The cells were cultured by $24 \mathrm{hs}$ at $37 \circ \mathrm{C}, 5 \% \mathrm{CO}_{2}$. One day later, when cells were approximately $70-80 \%$ confluent, the cells were washed twice with PBS and incubated with medium without serum for 48 hs. After, the cells were transduced with adeno-associated virus (AAV)-GFP vector with medium (MEM Engle) without FBS and antibiotic with MOI 100, 1000 and 5000 and compared to normal protocol. Cells were incubated at $37{ }^{\circ} \mathrm{C}, 5 \% \mathrm{CO}_{2}$ for $24 \mathrm{hs}$ and the medium (MEM Engle) with FBS $20 \%$ for $24 \mathrm{hs}$. The medium was changed to MEM Engle $10 \%$ FBS. The medium was change every day. Ten days after the transduction the number fluorescent cells per well were quantified with Confocal microscopy. The Figure 5 shows that the transduction efficiency was most efficient with the normal protocol than the starving protocol.

\subsubsection{Four factor transduction efficiency}

To improve the transduction efficiency we tested the 4 factors together as well separately. Using the normal protocol the cells were cultured by $24 \mathrm{hs}$ at $37{ }^{\circ} \mathrm{C}, 5 \% \mathrm{CO}_{2}$. One day later, the cells were transduced with adeno-associated virus (AAV)-Oct 3/4-GFP vector for $24 \mathrm{hs}$. Two days later, the cells were transduced with c-myc. Three days later, the cells were transduced with Sox2 plus Klf-4 with medium (MEM Engle) without FBS with MOI 10, 100 and MOI 1000.

Also, using the normal protocol the cells were transduced with adeno-associated virus (AAV)-Oct 3/4-GFP vector plus Sox2, Klf-4 and c-myc with medium (MEM Engle) without FBS with MOI 10, 100 and 1000. After 24 hs the medium was changed to MEM Engle 10\% FBS. The medium was change every day. Ten days after the transduction the number fluorescent cells per well were quantified with confocal microscopy. The Table 1 shows that 
the positive GFP cells were not different when the transduction was done with the 4 factors together as separately as well.

\section{MOI 50}

$2.1 \pm 1.2$

GFP positive cells/field

MOI 100

$3.2 \pm 1.2$

GFP positive cells/field

MOI 250

$6.9 \pm 3.4$

GFP positive cells/field

MOI 500

$12.2 \pm 4.4$

GFP positive cells/field

MOI 1000

$19.7 \pm 7.7$

GFP positive cells/field
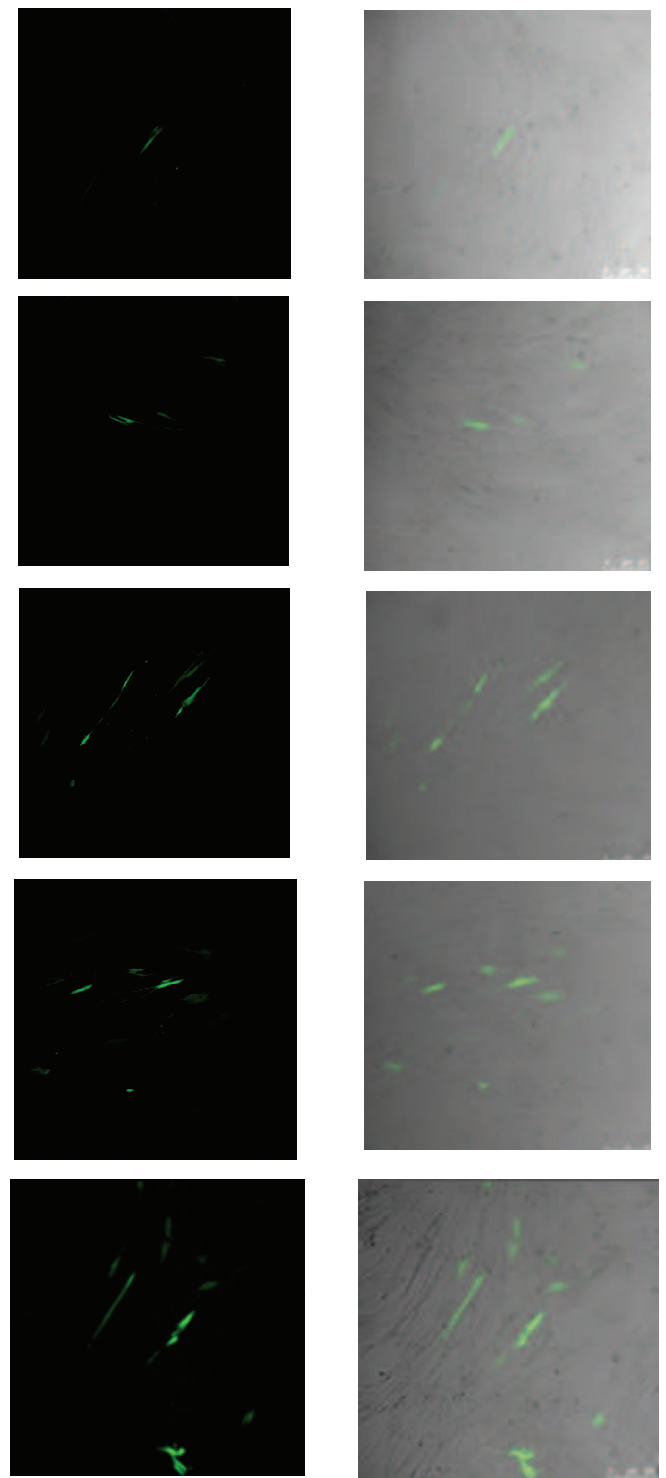

Fig. 4. AAV-GFP vector transduction. The green fluorescent cells indicate the GFP expression analyzed by Confocal Microscopy (x250) inIMR-90 cells. The figure shows on the left the GFP positive cells/ field and dark field, and on the right the merge cells. A vector pUF11 (an adeno-associated virus (AAV)-based plasmid vector) consisting GFP (535bp) was transduced in human fetal fibroblasts with MOI 50, 100, 250, 500 and 1000. 
A
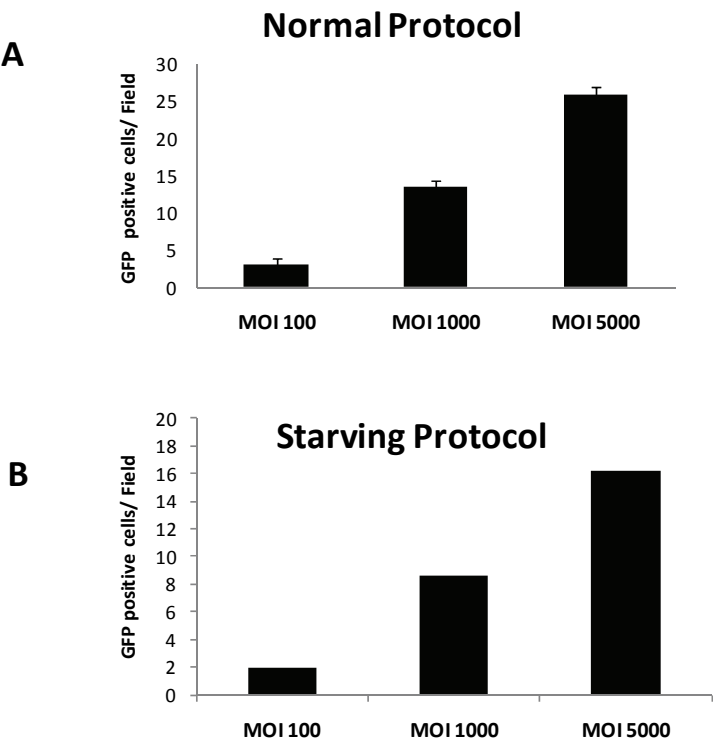

Fig. 5. The cells were cultured by $24 \mathrm{hs}$ at $37{ }^{\circ} \mathrm{C}, 5 \% \mathrm{CO}_{2}$. When cells were approximately $70-$ $80 \%$ confluent, the cells were washed PBS and transduced with adeno-associated virus (AAV)-GFP vector. A vector pUF11 (an adeno-associated virus (AAV)-based plasmid vector) consisting GFP (535bp) was transduced in human fetal fibroblasts with MOI 100, 1000 and 5000. Ten days after the transduction the number fluorescent cells per well were quantified with confocal microscopy. A. Show that the transduction efficiency with the normal protocol B. Show the transduction efficiency with the starving protocol. The figure shows that the transduction efficiency was most efficient with the normal protocol than starving protocol.

\begin{tabular}{|l|l|l|l|}
\hline & MOI 10 & MOI 100 & MOI 1000 \\
\hline Together & 1 & 7 & 84 \\
\hline Separately & 1 & 9 & 85
\end{tabular}

Table 1. Transduction of 4 factors together or separately as well, 10 days after the IMR-90 cells transduction. The results are expressed by GFP positive cells per well.

\subsubsection{Four factor delivery 20 and 40 days after transduction}

To test the delivery of the 4 factors transcription genes during hole the pluripotency induction time, the cells were transducted using the normal protocol with adeno-associated virus (AAV)-Oct 3/4-GFP vector plus Sox2, Klf-4 with and without c-myc with medium (MEM Engle) without FBS and antibiotic with MOI 1000 (Experiment 1 and Experiment 2) (Figure 6). After $24 \mathrm{hs}$ was added $1 \mathrm{ml} /$ well medium $30 \%$ serum for 6 hs. The medium was changed MEMEngle $10 \%+\mathrm{P} / \mathrm{S}$ and changed each 2 or 3 days. Twenty and 40 days after 
transduction the RNA was extracted with Trizol to quantify the GFP, Oct3/4, Sox-2, Klf-4 and c-Myc by RT-PCR, using the primers described above. Several different groups were tested to confirm effectiveness samples as showed by RT-PCR of agarose gel samples in the Figure 6.

Experiment 1: 20 days after transduction:

a. Control cells,

b. Oct 3/4-GFP,

c. Oct 3/4-GFP + Sox-2 + Klf-4 with c-Myc,

d. Oct 3/4-GFP + Sox-2 + Klf-4 without c-Myc.

Experiment 2: 40 days after transduction

a. Control cells,

b. Oct 3/4-GFP,

c. Oct 3/4-GFP + Sox-2 + Klf-4 with c-Myc,

d. Oct 3/4-GFP + Sox-2 + Klf-4 without c-Myc.

The figure 6 shows that the 4 factors are expressed for up 40 days.

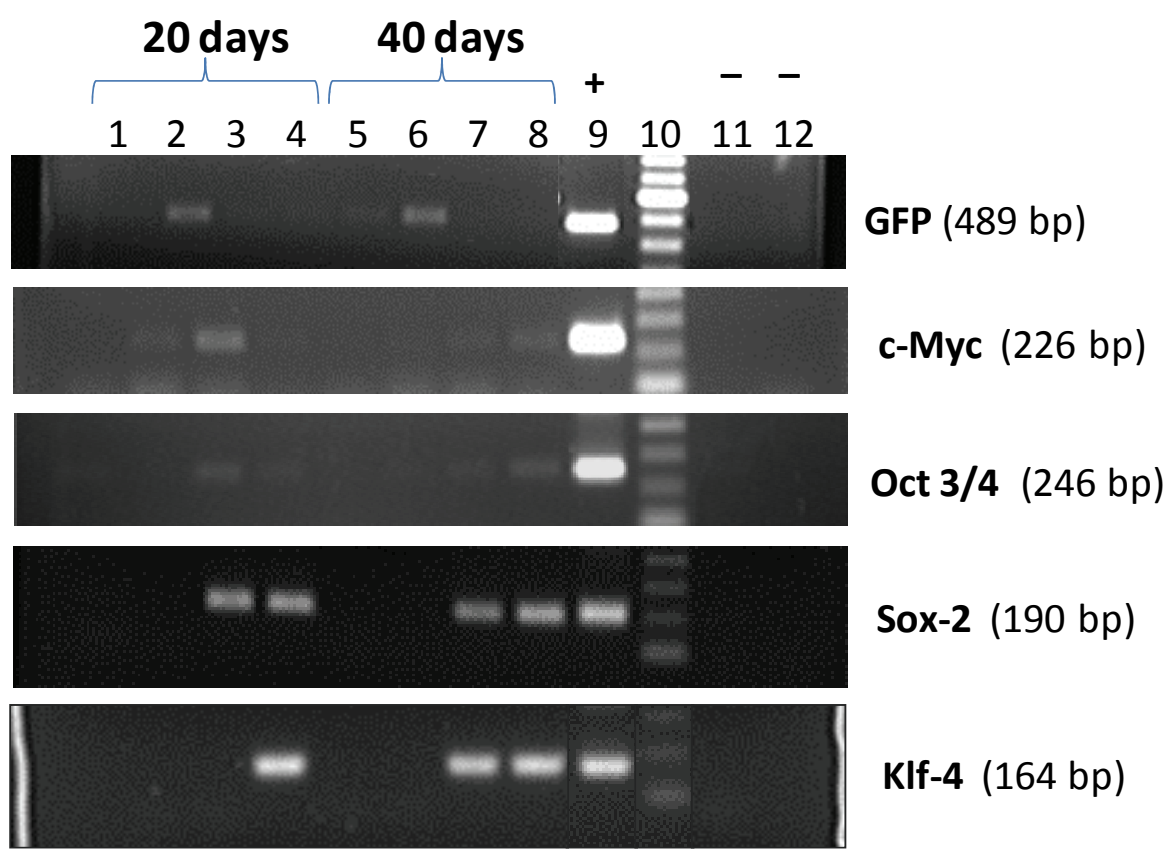

Fig. 6. RT- PCR results showing transcription factor gene expression after 20 days and 40 days transduction with AAV. All of the 4 markers are visible although Oct3/4 was weakly expressed. Sequences by RT-PCR of agarose gel samples from each experimental test group. Experiment 1: 20 days after transduction: a) Control: GFP b) With c-Myc c) Without cMyc. Experiment 2: 40 days after transduction a) Control: GFP, b) With c-Myc c) Without cMyc . Positive control. Ladder 100, Negative Control $1^{\text {st }}$ reaction, Negative Control $2^{\text {nd }}$ reaction: The cells were transduced with and without c-Myc. $1.3 \times 10^{6}$ cells; $70 \%$ confluence; 4 P; MOI 1000. 


\subsubsection{HEP G2 liver cells}

Heptocyte Cells: HepG2 Cell line was derived from the hepatocellular carcinoma cell line (ATCC - Hep G2/2.2.1); adherent; epithelial; from a 15 year old male Caucasian.

For human hepatocytes cells, 6 days after rAAV-GFP (Figura 7 A and B) and rAAV-Oct 3/4GFP (Figure $7 \mathrm{C}$ and D) (MOI-100) transduction, the GFP positive cells were observed by Confocal microscopy and total RNA was extracted with Trizol and the GFP and Oct 3/4 gene expression were determined by RT-PCR (Figure $7 \mathrm{E}$ and F). Microscopically the rAAVGFP could be clearly seen expressed in the cells, however rAAV-Oct 3/4-GFP was not observed.
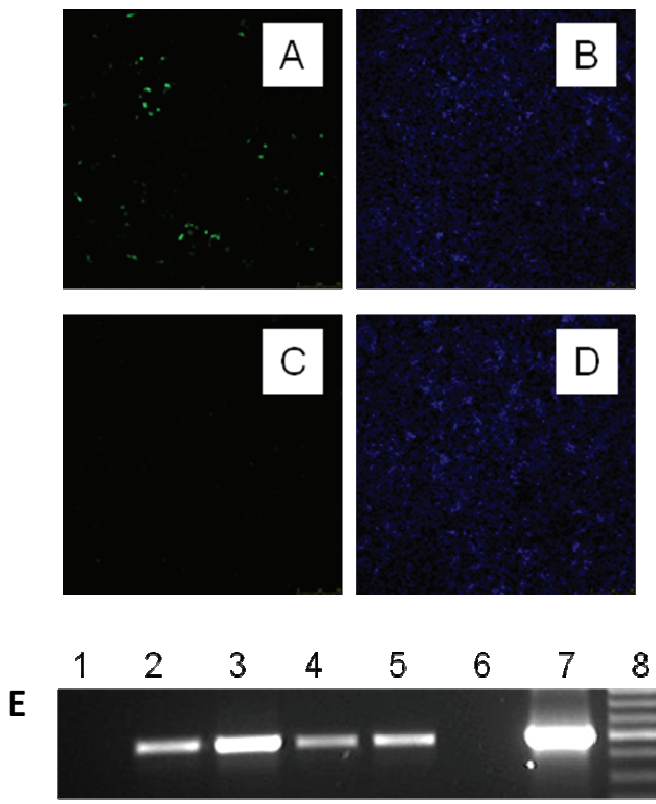

GFP (489 bp)

$\mathbf{F}$

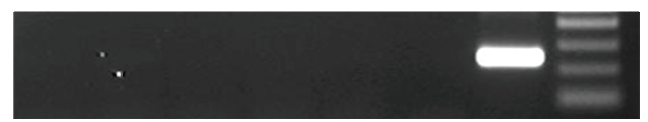

Oct 3/4-GFP (246 bp)

Fig. 7. Human Hepatocytes Cells, 6 days after transduction. Upper Panel: A. Confocal microscopy rAAV-GFP (MOI-100) and B. DAPI. C. rAAV-Oct3/4-GFP (MOI-100) and D. DAPI. Lower Panel: E. RT-PCR for GFP and F. Oct3/4-GFP. 1- Control; 2- GFP MOI 10; 3GFP MOI 100; 4- Oct 3/4 - GFP MOI 10; 5-Oct 3/4 - GFP MOI 100; 6- Negative Control; 7Positive Control; and 8- Ladder.

\subsection{3 iPS Cells generation with rAAV}

Since the question was: can we make iPScells with rAAV-GFP instead of retroviruses, lentivirus or adeno-virus we started with the same four transcription genes used by Yamanka who kindly provided them to us.

The IMR-90 a fetal skin fibroblast and HEP G2 liver cells were plated $1.3 \times 10^{6}$ cells with $70 \%$ confluence the cells transduced with Oct3/4, Sox-2 and Klf-4 with c-Myc and without c- 
Myc, MOI 1000. Before transduction the medium was changed to medium without serum and antibiotic for $24 \mathrm{hs}$. The transduction was done with 4 factors together. After $24 \mathrm{hs} 30 \%$ serum was added $1 \mathrm{ml} /$ well for $6 \mathrm{hs}$. The medium was changed to MEMEngle $10 \%+\mathrm{P} / \mathrm{S}$ for 3 days. The medium was changed to hESC medium 4 days after the transduction (Knockout DMEM supplemented with 15\% knockout serum replacement, L-glutamine, nonessential amino acids, $\beta$-mercaptoethanol and penicillin/streptomycin). For the generation of iPS with rAAV transduction the cells were not cultured in MEFs or with chemicals treatment. The medium was changed every day. iPS colonies were picked between 20-30 days post transduction based on colony morphology. To HEP G2 liver cells 15 days after the transduction the cells were passage and re-transduced.

The medium was changed every day until the colonies become big enough to be picked out. Colonies should first become visible approximately a week after the transduction. They become large enough to be picked out around day 20. The reprogrammed clones were selected by morphological criteria (compact colonies, high nucleous to cytoplasm ratio and proeminent nucleoli) as showed Figure 8.
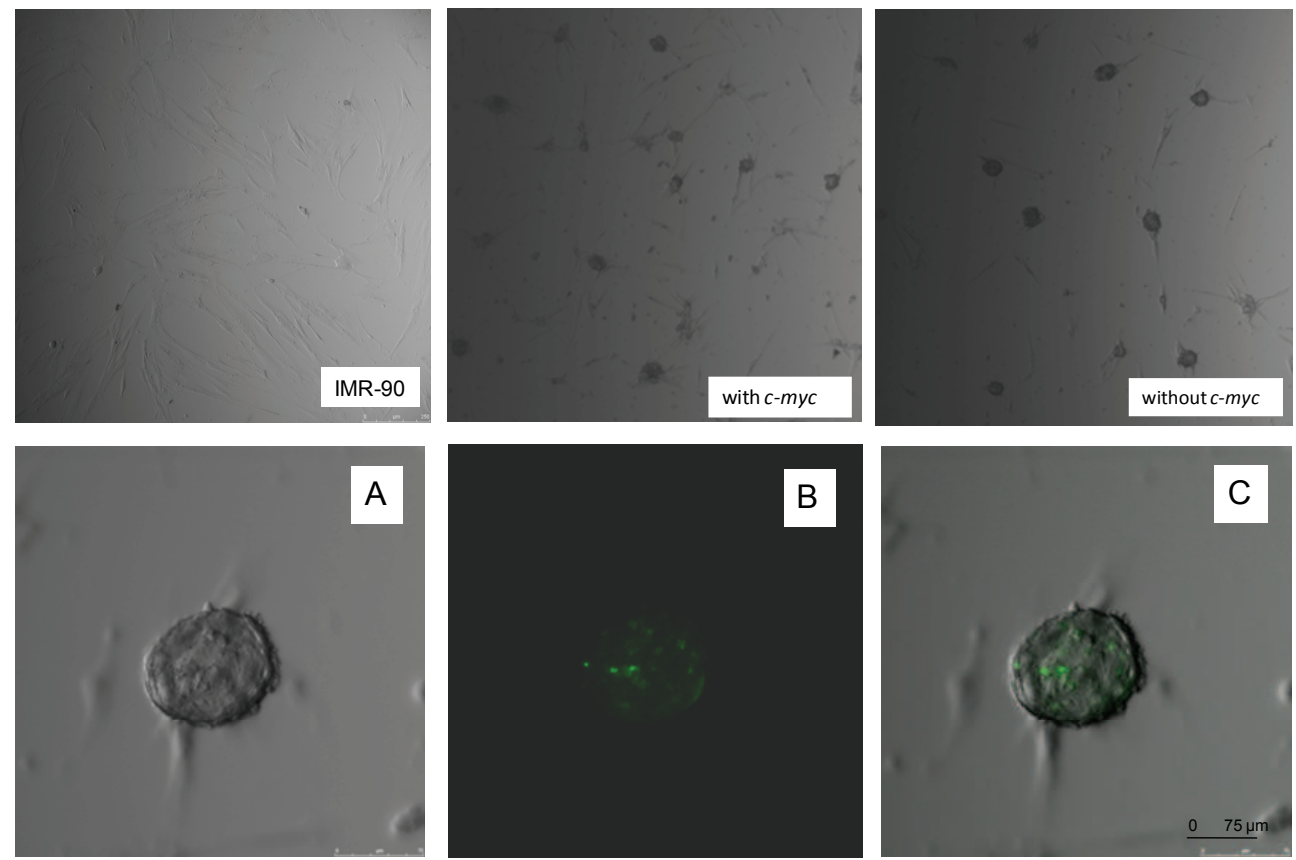

Fig. 8. iPS cells from IMR-90 fibroblast cells. Upper Panel: iPS cells confocal microscopy image. Before transduction (IMR-90), iPS cells with 4 factors (with c-Myc), and iPS cells with 3 factors (without c-Myc). Lower Panel: iPS cells without c-Myc. Confocal image with bright field (A), fluorescence (B), merge (C).

Picking out the colonies: aliquot $20 \mu \mathrm{l}$ of $0.25 \%$ trypsin/ $1 \mathrm{mM}$ EDTA per well of 96-well plate. The medium was removed from the dish, and added $10 \mathrm{ml}$ of PBS. Aspirate PBS, and added $5 \mathrm{ml}$ of PBS. Pick colonies from the dish using a Pipetman set at $2 \mu \mathrm{l}$, and transfer it into the 96-well trypsin plate. We picked out as many colonies as we can within $15 \mathrm{~min}$. 
Cells was incubated another $15 \mathrm{~min}$ in trypsin at $37{ }^{\circ} \mathrm{C}$ to dissociate cells in the colonies. 180 $\mu \mathrm{l}$ of ES medium was added to each well, and pipetted up and down to break up the colony to single cells. The cell suspension was transferred into the well of 24-well plates with medium without feeder cells, and $300 \mu \mathrm{l}$ ES medium added. The cells were incubated in $37{ }^{\circ} \mathrm{C}, 5 \% \mathrm{CO} 2$ until the cells reach $80-90 \%$ confluence. At this point they were passaged into 6-well plates.

\subsubsection{Alkaline phosphatase (AP) and immunofluorescence staining}

To demonstrate these cells possess characterists of embryonic stem cells, we stained them for AP activity using a kit (CHEMICON®s Alkaline Phosphatase Detection) and the expression of membrane markers, Cell surface Stage-Specific Embrionic Antigens (SSEA-4) and Keratan sulphate-associated antigens (TRA-1-60 and TRA-1-81) using a kit (CHEMICON®s ES Cell Marker Samples) and the transcription factor Oct-4.

Alkaline Phosphatase staining was used as a marker for embryonic-like stem cells .The AP was quantified 20 days after treatment with hESC medium. Figure 8 shows the AP to HEP G2 liver cells and Figure 9 show the iPS cells membrane markers from Human hepatocyte cells (HEP G2).

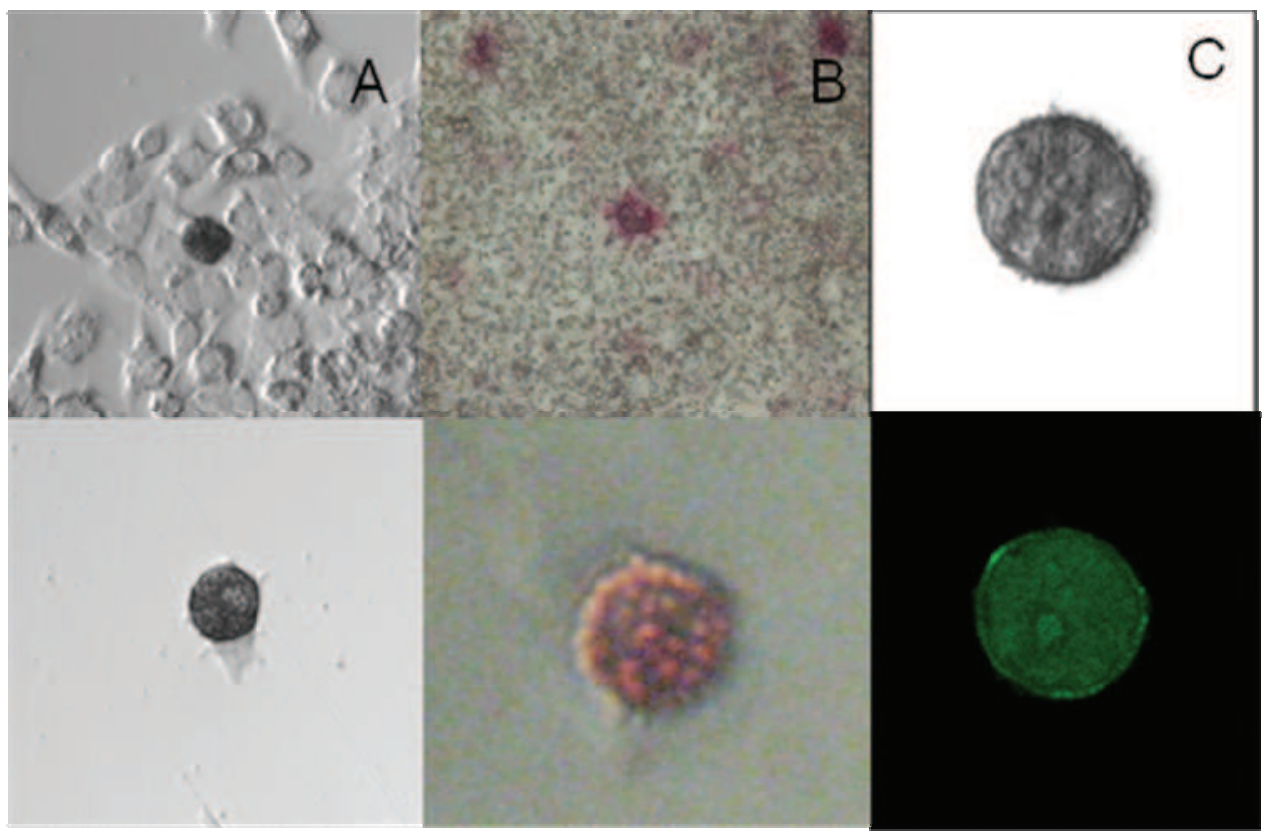

Fig. 9. iPS from Human hepatocyte cells (HepG2).Upper and down panels (A) Confocal bright-field, (B) alkaline phosphatase positive and (C) Hepatocytes cells transduced with 4 factors, 30 days after transduction. Upper, bright-field and down, GFP positive iPS (Oct-3/4 positive). 
Figure 10 show the AP to IMR-90 fibroblast cells and Figure 11 show the iPS cells membrane markers from Human fibroblast cells (IMR-90). The iPS cells shows morphology such as compact colonies, high nucleus to cytoplasm ratio and prominent nucleoli. The testing for markers of human embryonic stem cells in the AAV induced iPS cells was positive.

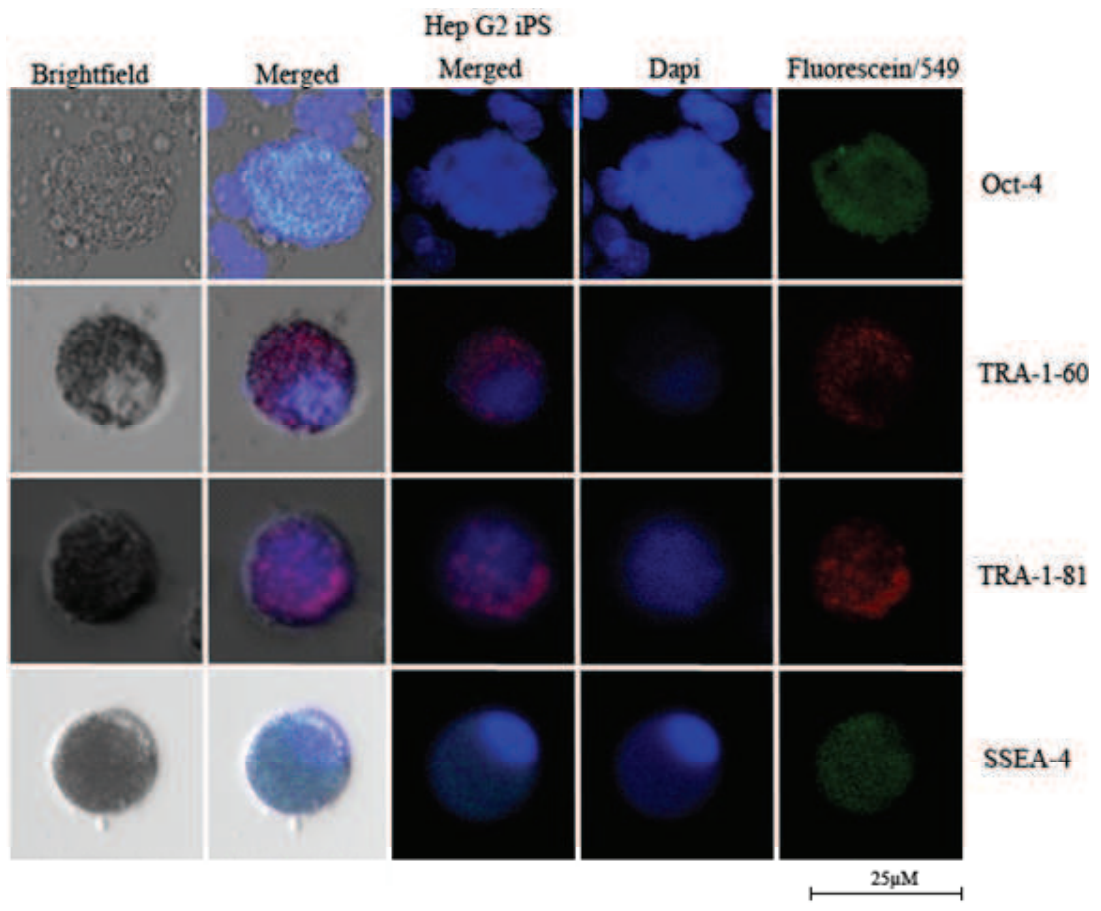

Fig. 10. iPS from Human hepatocyte cells (HepG2). iPS cells membrane markers: the transcription factor Oct-4; Keratan sulphate-associated antigens (TRA-1-60 and TRA-1-81) and Cell surface Stage-Specific Embrionic Antigens (SSEA-4).
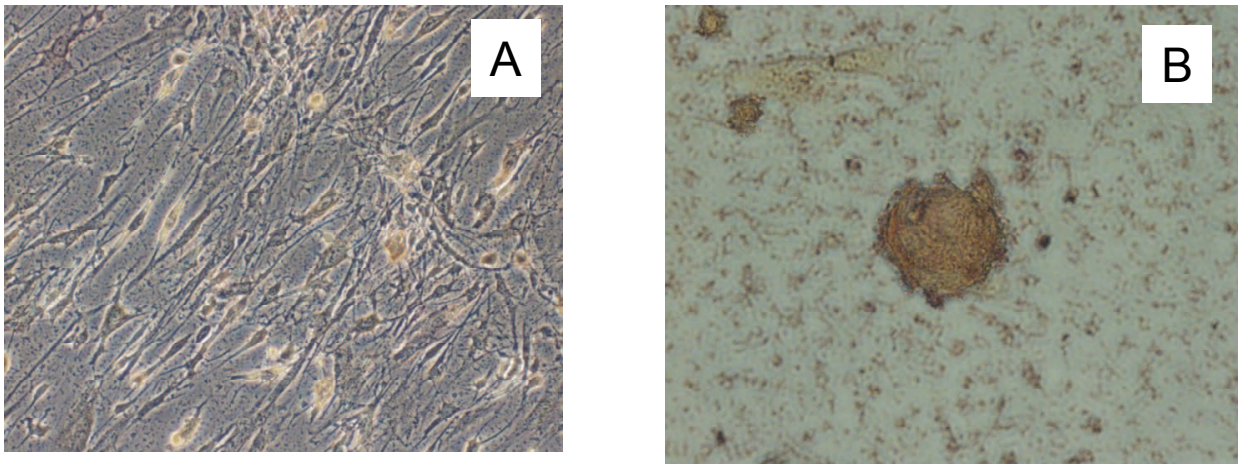

Fig 11. iPS from Fibroblast Human Cells (IMR-90). A. Control cells, B. Alkaline phosphatase positive. 


\section{IMR-90 iPS}

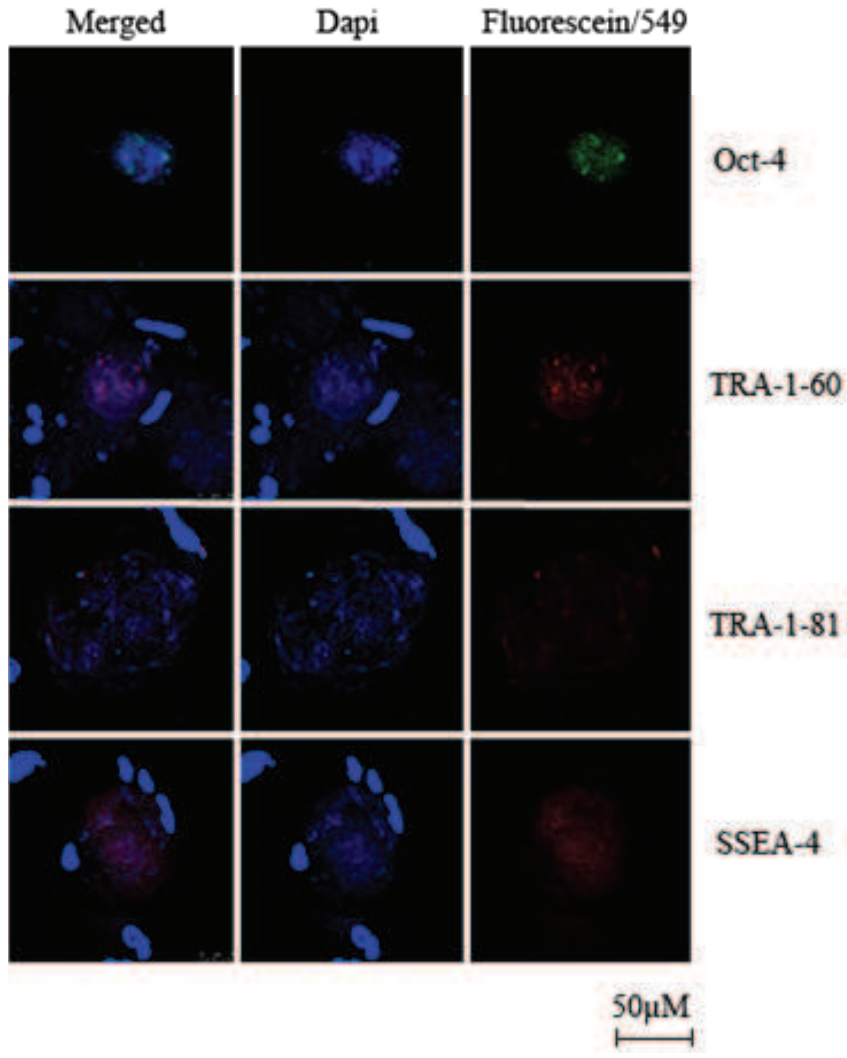

Fig. 12. iPS from Fibroblast Human Cells (IMR-90). iPS cells membrane markers: the transcription factor Oct-4; Keratan sulphate-associated antigens (TRA-1-60 and TRA-1-81) and Cell surface Stage-Specific Embrionic Antigens (SSEA-4).

\section{Discussion}

In the present paper we report the application of AAV serotype 2 as a vector for producing human iPS cells from adult somatic liver and cells. We delivered the transcription factors: Oct 4, Sox2, c-Myc and Klf4 that were originally used by S. Yamanaka et al (Takahashi et al 2007). We are well aware that this set of factors is not the optimal choice except for Oct 4 and Sox2. Many other factors can replace cMyc and Klf4. However for the demonstration that AAV is an appropriate vector for reprogramming adult cells to iPS cells, we chose to work with the factors that have consistently been used for efficient conversion of differentiated somatic cells. In future studies with AAV we plan to test replacement factors. While more in vivo tests are necessary, this report establishes a feasible new method for producing iPS cells with AAV

rAAV has not previously been used as the viral vector for delivery of transgenes to induce pluripotent cells. AAV has several advantages over other viral vectors. Unlike retroviruses 
(and wild type AAV), rAAV does not integrate into the chromosomes. Therefore it does not raise concerns about insertional mutagenesis. This is confirmed by the safe and stable experience in several human trials with $\mathrm{rAAV}$ (Maguire et al , 2008). Originally retroviruses were the vectors of choice for delivery of transcription factors (Takahashi et al 2007). However, they are unsuitable for human use because of oncogenic risks from insertional mutagenesis. Lentivirus has a large carrying capacity, but it is a retrovirus. As the virus type for HIV the public might be concerned about its use in iPS cells for autologous transplantation. The adenovirus has been tested as a non-integrating virus. The results were positive but not efficient (Stadtfield et al, 2008). Using adenovirus as a vector is appealing for its ease of production and use, although such studies overlook that the adenovirus is not a viable vector for humans. The adenovirus caused fatal effects in the failed gene therapy trial at University of Pennsylvania in 1999 (Marshall, 2009). Thus even though these vectors might be better developed and even though they may serve the purpose of making iPS cells, they carry a negative public image for human use. The leading viral vector in several successful clinical trials recently has been the recombinant adenoassociated virus vector (rAAV). Experience with rAAV in humans is safe, stable, producible in high titers ( $10^{12}$ infectious particles per $\mathrm{ml}$ ) and non-immunogenic (Maguire et al 2008). In this paper we propose that rAAV is an advantageous vector for producing human iPS cells for therapeutic transplantion.

However only a few papers in the literature have explored AAV and iPS and those reports used AAV for specialized purposes. Khan et al (2010) showed that AAV can selectively target mutations and correct mutations in iPS cells by homologous recombination. They used AAV in specifically generated human iPS cells with two different gene mutations (HPRT1 and HMBA1) responsible for the Lesch-Nyan syndrome. They studied fibroblasts and mesenchymal cells as the adult cell sources that had been reprogrammed with Oct4, Sox2 Lin28 NANOG as the transgenes. Reprogramming was conventional with a lentivirus. The successful correction of a mutation in the iPS cells extends the usefulness of AAV beyond making iPS cells to making iPS cells better. If autologous adult somatic cells have a mutation that can be corrected by gene targeting with AAV, they become available for therapeutic purposes. Targeting with AAV was achieved without cytotoxicity (Kahn et al 2010). A similar paper report from Mitsui et al (2009), who received iPS cells directly from $S$ Yamanaka, tested AAV targeting of HPRT1.

Very recently (as we go to press) a new development in iPS production has indicated that a single microRNA may be able to effect the whole reprogramming process without resorting to transcription factors for delivery. (Anoke-Danso et al April 7, 2011). This new concept would be another use for AAV because AAV is excellent for delivery of miRNA (Qiao et al 2011). It is too soon to tell which method will ultimately make iPScell a successful alternative to embryonic stem cells or not.

\section{Conclusion}

In conclusion, several different types of vectors and delivery systems have been used to reprogram adult somatic cells to iPS cells but none have become predominantly useful. Here we show that rAAV is successful in delivering transcription factors to adult fibroblasts and hepatic cells and reprogramming them to iPS cells. rAAV is efficient and effective. We used low MOIs. Each of the 4 transcription factor was delivered in a separate rAAV plasmid so that in future applications the transgenes can be easily varied. There was no evidence of 
cytotoxicity and the iPS cells were stable. The iPS cell showed the accepted in vitro characteristics of being inducible Pluripotent Stem Cells, including cell morphology, alkaline phoshphatase positive staining, and SSEA1 positive staining. Doxocyclin was not required, making it simpler to use than the doxocyclin lentivirus method. While more in vivo tests are necessary, this report establishes a feasible new method for producing iPS cells with AAV. Other studies indicate AAV will be having the added advantage of being used for accurate targeting of mutations in iPS so that the mutations can be corrected by homologous recombination. With these advantages the use of AAV can move the technology of iPS closer to therapeutic use in human patients.

\section{Aknowledgment}

Oliveira EM was the recipient of a CNPq-PDE Fellowship (No.200994/2007-7) and from Dr MI Phillips Grant in USA. E. M. Oliveira holds scholarships from CNPq, Brazil. Dr. MI Phillips was supported by grant from NIH 1 R01 HL 077602.

\section{References}

Anokye-Danso, F., Trivedi, C.M. Juhr D., Gupta, M., Cui, Z., Tian, Y., Zhang, Y., Yang, W., Gruber, P.J., Epstein, J.A., \& Morrisey, E.E. (2011). Highly efficient miRNAmediated reprogramming of mouse and human somatic cells to pluripotency Cell Stem Cell 8: 376- 388.

Chang, C-W., Lai, Y-S., Pawlik, K.M., Liu, K., Sun, C.-W., Li, C., Schoeb, T.R. \& Townes, T.M. (2009). Polycistronic lentiviral vector for "hit and run" reprogramming of adult skin fibroblasts to induced pluripotent stem cells, Stem Cells 27, 1042-1049

Dimos, J.T., Rodolfa, K.T., Niakan, K.K., Weisenthal, L.M., Mitsumoto, H., Chung, W., Croft, G.F., Saphier, G., Leibel, R., Goland, R., Wichterle, H., Henderson, C.E. \& Eggan, K. 2008. Induced pluripotent stem cells generated from patients with ALS can be differentiated into motor neurons. Science. Aug 29;321(5893):1218-21.

Jia, F., Wilson, K.D., Sun, N., Gupta, D.M., Huang, M., Li, Z., Panetta, N.J., Chen, Z.Y., Robbins, R.C., Kay, M.A., et al. (2010). A nonviral minicircle vector for deriving human iPS cells. Nat. Methods 7, 197-199.

Khan, I.F., Kirata, R.K., Wang, P., Kho, J., Nelson, A., Huo, Y., Zavaljeski, M., Ware, C. \& Russell, D.W. (2010). Engineering of Human Pluripotent Stem Cells by AAVmediated Gene Technology. Molecular Therapy 18, 1192-1199.

Kaji, K., Norrby, K., Paca, A., Meileikovsky, M., Mohseni, P. \& Woltjen, K. (2009). Virus-free induction of pluripotency and subsequent excision of reprogramming factors. Nature 458, 771-775.

Maguire, A.M., Bennett, J.B. et al. (2008). "Safety and efficacy of gene transfer for Leber's congenital amaurosis. New England Journal of Medicine 358 (21): 2240-8.

Marshall, E. "Gene Therapy Death Prompts Review of Adenovirus Vector." (1999). Science 286: 2244-245.

Mitsui, K., Suzuki, K., Aizawa, E., Kawase, E., Suemori, H., Nakatsuji, N. \& Mitani, K. (2009). Gene targeting in human pluripotent stem cells with adeno-associated virus vectors. BBRC 388, 711-717.

Okita, K., Nakagawa, M., Hyenjong, H., Ichisaka, T. \& Yamanaka, S. (2008). Generation of mouse induced pluripotent stem cells without viral vectors. Science 322, 949-953. 
Phillips, M.I., Qian, K., Shen, L., Tang, Y.L. \& Oliveira, E.M. (2010). Gene Therapy Strategies: Constructing an AAV Trojan Horse. In: Genomics Essential Methods (Ed.), pp 283-306, Mike Starkey and Ramnath Elaswarapu.(Eds ). John Wiley \& Sons Ltd, Hoboken, New Jersey, USA.

Qiao, C., Yuan, Z., Ji, L., He, B., Zheng, H., Mayer, C., Li, J. \& Xiao, X. ( 2011). Liverspecific microRNA-122 target sequences incorporated in AAV vectors efficiently inhibits transgene expression in the liver Gene Therapy 18, 403-410

Stadtfeld, M., Nagaya, M., Utikal, J., Weir, G. \& Hochedlinger, K. (2008). Induced pluripotent stems cells generated without viral integration. Science 322, 945-949.

Takahashi, K., Tanabe, K., Ohnuki, M., Narita, M., Ichisaka, T., Tomoda, K., \& Yamanaka, S. (2007). Induction of pluripotent stem cells from adult human fibroblasts by defined factors. Cell 131, 861-872.

Warren, L., Manos, P.D., Ahfeldt, T., Loh, Y., Li, H., Lau, F., Ebina, W., Mandal, P.K., Smith, Z.D., Meissner, A., Daley, G.Q., Brack, A.S., Collins, J.J., Cowan, C., Schlaeger, T.M. \& Rossi, D.J. (2010). Highly Efficient Reprogramming to Pluripotency and Directed Differentiation of Human Cells with Synthetic Modified mRNA. Cell Stem Cell 7, 113.

Woltjen, K., Michael, I.P., Mohseni, P., Desai, R., Mileikovsky, M., Hämäläinen, R., Cowling, R., Wang, W., Liu, P., Gertsenstein, M., et al. (2009). piggyback transportation reprograms fibroblasts to induced pluripotent stem cells. Nature 458, 766-770.

Yu, J., Hu, K., Smuga-Otto, K., Tian, S., Stewart, R., Slukvin, I.I. \&Thomson, J.A. (2009). Human induced pluripotent stem cells free of vector and transgene sequences. Science 324, 797-801.

Zhou, H., Wu, S., Joo, J.Y., Zhu, S., Han, D.W., Lin, T., Trauger, S., Bein, G., Yao, S., Zhu, Y., et al. (2009) Generation of induced pluripotent stem cells using recombinant proteins. Cell Stem Cell 4, 381-384.

Zolotukhin, S., Byrne, B.J., Mason, E., Zolotukhin, I., Potter, M., Chesnut, K., Summerford, C., Samulski, R.J. \& Muzyczka, N. (1999). Gene Ther. Recombinant adenoassociated virus purification using novel methods improves infectious titer and yield. Jun;6(6):973-85. 


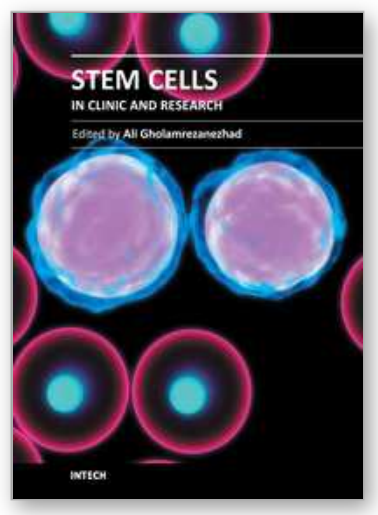

\author{
Stem Cells in Clinic and Research \\ Edited by Dr. Ali Gholamrezanezhad
}

ISBN 978-953-307-797-0

Hard cover, 804 pages

Publisher InTech

Published online 23, August, 2011

Published in print edition August, 2011

Based on our current understanding of cell biology and strong supporting evidence from previous experiences, different types of human stem cell populations are capable of undergoing differentiation or trans-differentiation into functionally and biologically active cells for use in therapeutic purposes. So far, progress regarding the use of both in vitro and in vivo regenerative medicine models already offers hope for the application of different types of stem cells as a powerful new therapeutic option to treat different diseases that were previously considered to be untreatable. Remarkable achievements in cell biology resulting in the isolation and characterization of various stem cells and progenitor cells has increased the expectation for the development of a new approach to the treatment of genetic and developmental human diseases. Due to the fact that currently stem cells and umbilical cord banks are so strictly defined and available, it seems that this mission is investigationally more practical than in the past. On the other hand, studies performed on stem cells, targeting their conversion into functionally mature tissue, are not necessarily seeking to result in the clinical application of the differentiated cells; In fact, still one of the important goals of these studies is to get acquainted with the natural process of development of mature cells from their immature progenitors during the embryonic period onwards, which can produce valuable results as knowledge of the developmental processes during embryogenesis. For example, the cellular and molecular mechanisms leading to mature and adult cells developmental abnormalities are relatively unknown. This lack of understanding stems from the lack of a good model system to study cell development and differentiation. Hence, the knowledge reached through these studies can prove to be a breakthrough in preventing developmental disorders. Meanwhile, many researchers conduct these studies to understand the molecular and cellular basis of cancer development. The fact that cancer is one of the leading causes of death throughout the world, highlights the importance of these researches in the fields of biology and medicine.

\title{
How to reference
}

In order to correctly reference this scholarly work, feel free to copy and paste the following:

Edilamar Menezes Oliveira and M Ian Phillips (2011). Associated Adeno Virus Vector for Producing Induced Pluripotent Stem Cells (IPS) for Human Somatic Cells, Stem Cells in Clinic and Research, Dr. Ali Gholamrezanezhad (Ed.), ISBN: 978-953-307-797-0, InTech, Available from: http://www.intechopen.com/books/stem-cells-in-clinic-and-research/associated-adeno-virus-vector-forproducing-induced-pluripotent-stem-cells-ips-for-human-somatic-cel

\section{INTECH}

open science | open minds 


\section{InTech Europe}

University Campus STeP Ri

Slavka Krautzeka 83/A

51000 Rijeka, Croatia

Phone: +385 (51) 770447

Fax: +385 (51) 686166

www.intechopen.com

\section{InTech China}

Unit 405, Office Block, Hotel Equatorial Shanghai No.65, Yan An Road (West), Shanghai, 200040, China

中国上海市延安西路65号上海国际贵都大饭店办公楼 405 单元 Phone: +86-21-62489820

Fax: +86-21-62489821 
(C) 2011 The Author(s). Licensee IntechOpen. This chapter is distributed under the terms of the Creative Commons Attribution-NonCommercialShareAlike-3.0 License, which permits use, distribution and reproduction for non-commercial purposes, provided the original is properly cited and derivative works building on this content are distributed under the same license. 